\title{
What's for dinner? Types of food served at family dinner differ across parent and family characteristics
}

\author{
Dianne Neumark-Sztainer ${ }^{1} *$, Rich MacLehose ${ }^{2}$, Katie Loth ${ }^{1}$, Jayne A Fulkerson ${ }^{3}$, \\ Marla E Eisenberg ${ }^{4}$ and Jerica Berge ${ }^{5}$ \\ 'Division of Epidemiology and Community Health, School of Public Health, University of Minnesota, 1300 South \\ Second Street, Suite 300, Minneapolis, MN 55454, USA: ${ }^{2}$ Division of Biostatistics, Division of Epidemiology \\ and Community Health, School of Public Health, University of Minnesota, Minneapolis, MN, USA: ${ }^{3}$ School of \\ Nursing, University of Minnesota, Minneapolis, MN, USA: ${ }^{4}$ Division of Adolescent Health and Medicine, \\ Department of Pediatrics, University of Minnesota, Minneapolis, MN, USA: ${ }^{5}$ Family Medicine and Community \\ Health, School of Medicine, University of Minnesota, Minneapolis, MN, USA
}

Submitted 27 January 2012: Final revision received 18 June 2012: Accepted 24 August 2012: First published online 19 October 2012

\begin{abstract}
Objective: To examine the types of food served at family dinner in the homes of adolescents and correlations with parent and family sociodemographic characteristics, psychosocial factors and meal-specific variables.

Design: A cross-sectional population-based survey completed by mail or telephone by parents participating in Project F-EAT (Families and Eating and Activity in Teens) in 2009-2010.

Setting: Homes of families with adolescents in Minneapolis/St. Paul urban area, MN, USA.

Subjects: Participants included 1923 parents/guardians (90.8\% female; $68 \cdot 5 \%$ from ethnic/racial minorities) of adolescents who participated in EAT 2010.

Results: Less than a third (28\%) of parents reported serving a green salad at family dinner on a regular basis, but $70 \%$ reported regularly serving vegetables (other than potatoes). About one-fifth (21\%) of families had fast food at family dinners two or more times per week. Variables from within the sociodemographic domain (low educational attainment) psychosocial domain (high work-life stress, depressive symptoms, low family functioning) and meal-specific domain (low value of family meals, low enjoyment of cooking, low meal planning, high food purchasing barriers and fewer hours in food preparation) were associated with lower healthfulness of foods served at family dinners, in analyses adjusted for sociodemographic characteristics.

Conclusions: There is a need for interventions to improve the healthfulness of food served at family meals. Interventions need to be suitable for parents with low levels of education; take parent and family psychosocial factors into account; promote more positive attitudes toward family meals; and provide skills to make it easier to plan and prepare healthful family meals.
\end{abstract}

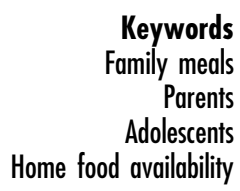

Keywords

Parents

Adolescents

Home food availability
Family meals are important for the health and well-being of adolescents. Past research examining family meal frequency has found that more frequent family meals are associated with positive outcomes in youth, including better dietary intake ${ }^{(1-14)}$, lower prevalence of overweight/ obesity $^{(6,14-17)}$, fewer disordered eating behaviours ${ }^{(8,18-30)}$ and higher levels of psychological well-being ${ }^{(31,32)}$. This body of research has stimulated interest in family meals among health professionals and the public and has led to questions on what family meals look like, particularly with regard to the types of foods being served. Learning more about what is served at family meals, and parent and family factors that are correlated with healthier meals, can help in guiding interventions to improve the home food environment.

Knowledge about how the types of foods served at family meals differ by sociodemographic characteristics can help in guiding decisions regarding who is in greatest need of intervention. Learning more about how psychosocial factors, such as parent work-life stress, parent depressive symptoms and family functioning (e.g. communication, problem solving, connectedness), are correlated with foods served at family meals may help to elucidate the types of factors that need to be taken into account in developing interventions ${ }^{(17,33)}$. Finally, knowledge about how meal-specific variables, such as attitudes towards 
family meals, food purchasing barriers, and meal planning and preparation practices, are associated with the types of foods served at family meals can help guide specific intervention messages ${ }^{(1,17)}$.

The present study builds upon the extant body of literature on family meals, which has primarily focused on frequency of family meals, by addressing the following research questions:

1. What types of foods are served at family dinners?

2. How are parent and family sociodemographic characteristics, psychosocial well-being and meal-specific variables associated with the type of food served at family dinners?

We focused on family dinners, rather than on other meals, because breakfast is likely to include different types of foods $^{(34)}$ and lunch seems less likely to be eaten on a regular basis as a family meal given school schedules. Factors hypothesized to be associated with healthier family dinners include higher levels of income and education, not working full time, higher levels of psychosocial well-being, more positive attitudes regarding family meals, fewer food purchasing barriers, enjoyment of cooking, and greater involvement in meal planning and food preparation ${ }^{(1,17,33)}$.

\section{Methods}

\section{Study population and design}

Data were drawn from Project F-EAT (Families and Eating and Activity among Teens), a cross-sectional, populationbased study of parents of adolescents. Project F-EAT surveys were completed by 3709 parents of adolescents enrolled in EAT 2010 (Eating and Activity in Teens).

The EAT 2010 study population includes adolescents from twenty public middle schools and high schools in Minneapolis/St. Paul, MN, USA, which serve socioeconomically and racially/ethnically diverse students. Adolescent participants in EAT 2010 reflect the diversity of enrolled schools; $71 \%$ qualified for free or reduced-price lunch and $81 \%$ were from ethnic/racial minority groups. Participants had a mean age of $14 \cdot 4($ SD $2 \cdot 0)$ years; $53 \cdot 2 \%$ were girls; $46 \cdot 1 \%$ were in middle school (6th-8th grades) and $53.9 \%$ were in high school (9th-12th grades). Adolescents from selected required health, physical education and science classes at each school completed surveys during the 2009-2010 school year. Among adolescents who were at school on the days of survey administration, 96.3\% had parental consent and chose to participate.

Each adolescent was asked to provide contact information for up to two parents (or other caregivers, as relevant) for participation in Project F-EAT. Overall, the response rate among parents in Project F-EAT was high: at least one parent responded for $85.3 \%(n$ 2382) of the adolescents and for $67 \cdot 9 \%(n$ 1327) of the adolescents who provided information on two parents, both parents responded. Parental response rates did not differ by adolescent gender, age, socio-economic status or language spoken at home but did differ by race/ethnicity, with the highest response rates among the parents of white adolescents.

The current analysis included only one parent (or other caregiver) per household ( $n$ 1923), to ensure independence of data. For families in which two parents responded, we selected the parent who reported that he/ she usually prepares food for the family on the F-EAT survey. If neither parent reported food preparation, we excluded that household from the current analysis ( $n$ 226). If more than one parent reported that they usually prepare food ( $n$ 495), we gave priority based on relationship to adolescent (e.g. preference to parents over step-parents) and parent gender (preference to females). Further, because the aim of the current analysis was to examine types of foods served at family meals, parents who indicated that they never eat family dinner (and did not report on the types of foods typically served) were excluded ( $n$ 93). Finally, parents who reported making meals but did not live with the participant most of the time ( $n$ 39) were excluded. The final analytic sample for the current analysis included 1923 parents (87\% were mothers, 8\% fathers and $5 \%$ step-parents or other parental figures); sample characteristics are shown in Table 1.

\section{Data collection}

Parents were initially mailed an invitation describing Project F-EAT and a telephone number to call if they preferred to complete the survey over the phone. A follow-up mailing included the Project F-EAT survey, a consent form and a postage-paid return envelope. Parents were mailed a reminder postcard after two weeks and a second copy of the survey if they did not respond within one month. Up to eight phone calls were made to contact non-responders and offer a telephone option for survey completion. Most (78\%) of the parent surveys were completed by mail. Both mailed surveys and phone interviews were available in English, Spanish, Hmong and Somali, and the phone interview was additionally offered in Oromo, Amharic and Karen languages. The majority of surveys (83\%) were completed in English. Data collection ran from October 2009 to October 2010 and was conducted by the Wilder Research Foundation in St. Paul, Minnesota. The University of Minnesota Institutional Review Board approved all study procedures.

\section{Survey development}

The Project F-EAT survey was designed to gather information on adolescents' family and home environments with relevance to dietary intake, physical activity and weight-related health. Social cognitive theory ${ }^{(35)}$ and an ecological framework ${ }^{(36)}$ guided the selection of constructs to be assessed, while specific survey items were drawn 
Table 1 Sociodemographic characteristics of the study population: primary parents who reported eating family meals ( $n$ 1923)*, Project F-EAT (Families and Eating and Activity in Teens), St. Paul, MN, USA, 2009-2010

\begin{tabular}{|c|c|c|}
\hline & Mean or $n$ & SD or $\%$ \\
\hline Age (years; $n$ 1855) (mean, sD) & $41 \cdot 6$ & $7 \cdot 9$ \\
\hline \multicolumn{3}{|l|}{ Gender $(n, \%)$} \\
\hline Female & 1746 & $90 \cdot 8$ \\
\hline Male & 176 & $9 \cdot 2$ \\
\hline \multicolumn{3}{|l|}{ Educational attainment $(n, \%)$} \\
\hline$<$ High school & 537 & $28 \cdot 2$ \\
\hline High school or GED & 387 & $20 \cdot 3$ \\
\hline Some college & 538 & $28 \cdot 2$ \\
\hline Finished college & 323 & $17 \cdot 2$ \\
\hline Advanced degree & 116 & $6 \cdot 1$ \\
\hline \multicolumn{3}{|l|}{ Household income level ( $n, \%)$} \\
\hline$<\$$ US 20000 & 664 & $36 \cdot 0$ \\
\hline \$US 20000-34 999 & 424 & $23 \cdot 0$ \\
\hline \$US $35000-49999$ & 281 & $15 \cdot 2$ \\
\hline \$US 50000-74999 & 226 & $12 \cdot 2$ \\
\hline$\geq \$ \cup S 75000$ & 251 & $13 \cdot 6$ \\
\hline \multicolumn{3}{|l|}{ Ethnicity/race $(n, \%)$} \\
\hline White & 597 & $31 \cdot 5$ \\
\hline Black & 544 & $28 \cdot 7$ \\
\hline Hispanic/Latino & 320 & $16 \cdot 9$ \\
\hline Asian American & 325 & $17 \cdot 2$ \\
\hline American Indian & 51 & $2 \cdot 7$ \\
\hline Other/mixed & 56 & $3 \cdot 0$ \\
\hline \multicolumn{3}{|l|}{ Work status $(n, \%)$} \\
\hline Full-time & 873 & $46 \cdot 2$ \\
\hline Part-time & 327 & $17 \cdot 3$ \\
\hline Stay-at-home caregiver & 261 & $13 \cdot 8$ \\
\hline Unemployed & 428 & $22 \cdot 7$ \\
\hline \multicolumn{3}{|l|}{ Marital status $(n, \%)$} \\
\hline Married or in committed relationship & 1141 & $60 \cdot 0$ \\
\hline Divorced/single/other & 762 & $40 \cdot 0$ \\
\hline \multicolumn{3}{|l|}{ Number of children $(n, \%)$} \\
\hline 1 & 411 & $22 \cdot 0$ \\
\hline 2 or 3 & 982 & $52 \cdot 4$ \\
\hline$>3$ & 477 & $25 \cdot 5$ \\
\hline
\end{tabular}

GED, General Education Development test.

*Due to missing values, numbers do not always total 1923.

from a previous Project EAT parent survey, corresponding measures from the EAT 2010 student survey and existing surveys from the scientific literature. New questions were also developed to address the study aims (e.g. foods served at family meals).

Initially, content area experts reviewed a draft of the Project F-EAT survey to ensure that key constructs of relevance to adolescent weight-related behaviours and outcomes were included. Further, survey appropriateness for the major cultural groups participating in the study (i.e. Native American, Hmong, Latino, Somali and AfricanAmerican groups) was addressed by having bi-cultural staff members from the Wilder Research Foundation review the survey and provide feedback. Next, three focus groups were conducted with twenty-eight parents (including both mothers and fathers) from diverse backgrounds to pre-test a draft of the survey. An additional sample of 102 parents completed the survey twice over two weeks, to examine test-retest reliability of survey questions. Finally, scale psychometric properties were examined within the full Project F-EAT sample.
Once a final version of the survey was developed in English, the written survey was professionally translated. Bilingual staff members at the Wilder Research Foundation reviewed the translated survey, edited translations when appropriate, and returned the updated surveys to the original translators for final review and approval.

\section{Measures}

Family meals

Types of foods served at family dinner. Types of foods served at family dinner were examined with six items designed to assess the frequency of foods served at family dinners, including: 'green salad', 'vegetables other than potatoes', '100\% fruit juice', 'fruit (not including juice)', 'milk' and 'sugar-sweetened beverages (soda pop, Kool-aid, etc.)'. Four response options ranged from 'never' to 'always' (individual item test-retest $r$ values ranged from 0.56 to 0.85$)$. An additional question was used to assess fast food: 'During the past week, how many times was a family meal purchased from a fast-food restaurant and eaten together either at the restaurant or at home (pizza counts)?'. Four response options ranged from 'never' to 'three or more times' (test-retest $r=0 \cdot 43$ ). These items were adapted from our previous research regarding home food availability and instrument development for family meals research ${ }^{(37,38)}$.

Overall healthfulness of foods served at dinner. Overall healthfulness of foods served at dinner was calculated as a summary score by adding points for each of the healthier foods (green salad, vegetables, $100 \%$ fruit juice, fruit and milk) and subtracting points for each of the unhealthy foods (sugar-sweetened beverages and fast food). Points were added (for healthy foods) and subtracted (for unhealthy foods) based on the frequency of serving each item: 0 points for 'never'; 1 for 'sometimes' (or 'once a week' for fast food); 2 for 'usually' (or 'twice a week' for fast food); 3 for 'always' (or 'three or more times a week' for fast food). The possible range for the summary score was -6 to 15 (test-retest $r=0 \cdot 80$ ). Negative values represent dinners that consist of greater unhealthy than healthy foods (for example, when salads, fruit, vegetables, fruit juice and milk are never served, but sugar-sweetened beverages and fast food are often served).

\section{Sociodemographic characteristics}

Educational attainment. Educational attainment was assessed with the question: 'What is the highest grade or year of school that you have completed?' (test-retest $r=0 \cdot 84)$.

Housebold income level. Household income level was assessed with the question: 'What was the total income of your household before taxes in the past year?' (test-retest $r=0 \cdot 94)$.

Race/ethnicity. Race/ethnicity was assessed with the question: 'Do you think of yourself as (i) white, (ii) black 
or African-American, (iii) Hispanic or Latino, (iv) AsianAmerican, (v) Hawaiian or Pacific Islander, or (vi) American Indian or Native American?' and respondents were asked to check all that apply (test-retest percentage agreement $=92 \%$ ). Due to small numbers, Hawaiian/ Pacific Islanders and people who checked more than one ethnic/racial group were combined.

Work status. Work status was assessed with the question: 'Which of the following best describes your current work situation?'. Response options included 'working full-time', 'working part-time', 'stay-at-home caregiver', 'currently unemployed but actively seeking work' and 'not working for pay' (test-retest $r=0 \cdot 82$ ).

Marital status. Marital status was assessed with the question 'What is your current marital status?' (test-retest percentage agreement $=98 \%$ ).

Number of children at home. Number of children at home was assessed with the question: 'How many children (under the age of 18) live in your household?' (test-retest $r=0 \cdot 99$ ).

Age. Finally, age was calculated using self-reported birth date and survey completion date.

\section{Psychosocial variables}

Work-life stress. Work-life stress was assessed using three items from previous research ${ }^{(39,40)}$ : 'Because of the requirements of my job, I miss out on home or family activities that I would prefer to participate in'; 'Because of the requirements of my job, my family time is less enjoyable or more pressured'; and 'Working leaves me with too little time or energy to be the kind of parent I want to be'. Four response options ranged from 'strongly disagree' to 'strongly agree'. A 'not employed' option was also included for each statement (Cronbach's $\alpha=0 \cdot 86$; test-retest $r=0 \cdot 75$ ). Categories of low, moderate and high stress were created such that approximately half of the sample was in the moderate stress group and a quarter in the high and low stress groups. This categorization allowed for the comparisons of the more extreme levels of work-life stress.

Parental depressive symptoms. Parental depressive symptoms were assessed with the five-item CES-Depression Scale: 'I felt depressed', 'My sleep was restless', 'I felt lonely', 'I had crying spells' and 'I could not get going' ${ }^{(41)}$. Four response options included 'rarely or none of the time', 'some or a little of the time', 'occasionally/moderate amount of the time' and 'most or all of the time' (Cronbach's $\alpha=0 \cdot 81$; test-retest $r=0 \cdot 76$ ). For analyses, individuals who scored 5.5 or above were categorized as having depressive symptoms and those who scored under $5 \cdot 5$ were categorized as not having depressive symptoms, as described previously $^{(41)}$.

Family functioning. Family functioning was assessed with the following five items: 'Family members are accepted for who they are'; 'Making decisions is a problem for the family'; 'We don't get along well together'; 'We can express feelings to each other'; and 'Planning family activities is difficult because we misunderstand each other' $^{\text {,42) }}$. Response options ranged from 'strongly disagree' to 'strongly agree' (Cronbach's $\alpha=0 \cdot 72$; test-retest $r=0 \cdot 67$ ). Higher scores were indicative of higher family functioning. Categories of low, moderate and high family functioning were created such that approximately half of the sample was in the moderate group and a quarter in the low and high functioning groups.

\section{Meal-specific variables}

Importance of family meals. Importance of family meals was assessed with a four-item scale: 'It is important that our family eat at least one meal a day together'; 'Different schedules make it hard to eat meals together on a regular basis'; 'In our family, it is often difficult to find a time when family members can sit down to a meal together'; and 'In our family, children are expected to be home for dinner'. Five response options ranged from 'strongly disagree' to 'strongly agree'. These items were adapted from the Family Eating Attitude and Behavior Scale $^{(43)}$ and used in Project EAT ${ }^{(30)}$. Categories of low, moderate and high importance were created such that approximately half the sample was in the middle group (Cronbach's $\alpha=0.52$; test-retest $r=0 \cdot 72$ ).

Food purchasing barriers. Food purchasing barriers were assessed with a four-item scale addressing cost, variety and quality of produce ${ }^{(44)}$, with response options ranging from 'strongly disagree' to 'strongly agree' (Cronbach's $\alpha=0.79$; test-retest $r=0.59$ ).

Enjoyment of cooking and meal planning. Enjoyment of cooking and meal planning were assessed with two separate items previously included in the Nepean Kids Growing Up Today Parent Questionnaire ${ }^{(45)}$ : 'I like trying new recipes' and 'I usually know or plan in the morning what we will eat for dinner that night'. Response options for both ranged from 'strongly disagree' to 'strongly agree' (test-retest $r=0.69$ and 0.62 , respectively). Responses were dichotomized into high and low for analyses.

Hours of food preparation. Hours of food preparation was asked with the questions: 'How many hours per week do you normally spend preparing food for your family?' and 'How many hours per week does your spouse, partner or other adult in the household spend preparing food for your family?' (test-retest $r=0 \cdot 68)^{(46)}$. Responses to the two questions were summed.

\section{Statistical analysis}

Descriptive statistics were used to examine sample sociodemographic characteristics. A series of logistic regression models adjusted for age, race, education, income, gender, work status, marital status and number of children were conducted to assess associations between parent/family characteristics and types of foods served regularly (i.e. usually or always) at family dinner. Analyses were run with and without adjustment for sociodemographic variables, which allowed for the attainment of significance tests for 
the remaining variables independent of sociodemographic differences. The crude estimates are useful in understanding the prevalence of a variable of interest (i.e. food served at family meals), whereas adjusted analyses can help in understanding the reasons for any differences (e.g. if differences across ethnicity/race are likely due to economic differences). Furthermore, comparisons between crude and adjusted estimates allow for a check of statistical validity; a large discrepancy between the two numbers can often be a sign of high correlation or sparse data (as well as possible confounding). In the current study, analyses generally revealed similar findings, thus we only present adjusted analyses. Using the fitted model, the probability of the dependent variable (e.g. serving green salad) was calculated for each person in the data set at a specified exposure level (e.g. less than high school education), given the individual's observed value of each adjustment variable. The average of these predicted probabilities is the adjusted percentage (e.g. for serving green salads among those with less than high school education) ${ }^{(47)}$. This procedure was repeated for each outcome at each level of the exposure variable. Associations between personal/demographic factors and overall healthfulness of food served at family meals were assessed using likelihood ratio tests from the logistic models. Individual pairwise tests were performed between each ethnic/racial group to allow more detailed examination of this important categorical variable. Statistical significance was defined as $P<0 \cdot 05$. Analyses were conducted using the Stata version 10 statistical software package.

\section{Results}

\section{Types of foods served at family dinner}

Green salad was served at family dinner on a regular basis (usually or always) in $28 \cdot 2 \%$ of the homes (Table 2).
In contrast, the majority of parents $(70 \cdot 1 \%)$ reported serving vegetables (other than potatoes) on a regular basis. Fruit and 100\% fruit juice were served on a regular basis in about a third of the homes. Milk was served on a regular basis in about half of the homes. About one-fifth $(22.0 \%)$ of the parents reported usually or always serving sugar-sweetened beverages at family dinners. Similarly, $21.0 \%$ of the parents reported having fast food at family meals two or more times per week.

\section{Parent/family characteristics: associations with foods served at family dinner}

\section{Sociodemographic characteristics}

Parent educational attainment showed strong inverse associations with overall healthfulness of foods served at family meals in analyses mutually adjusted for all sociodemographic characteristics (Table 3). Parents with lower levels of education were significantly less likely to serve vegetables $(P=0 \cdot 002)$ and more likely to serve sugar-sweetened beverages $(P=0 \cdot 013)$ and fast food $(P=0 \cdot 029)$ on a regular basis at family meals. Ethnic/ racial differences were found in the overall healthfulness of family meals and for specific foods. In general, whites and Asian Americans had the highest overall scores, although differences between the groups were not all statistically significant. Given the large ethnic/racial differences in serving milk at family meals, and both cultural and biological reasons for these practices, analyses for overall healthfulness scores were also run without including milk; patterns were found to be similar and are not presented here. Consistent associations were not found between work status and different types of foods served at family meals. The association between work status and the summary score for overall healthfulness of foods served at family meals bordered on statistical significance $(P=0 \cdot 058)$, with the lowest scores reported by parents working full time.

Table 2 Frequency of foods served at family dinners, as reported by primary parents $(n 1923)^{\star}$, Project F-EAT (Families and Eating and Activity in Teens), St. Paul, MN, USA, 2009-2010

\begin{tabular}{|c|c|c|c|c|c|c|c|c|}
\hline \multirow[b]{3}{*}{ Foods typically served at family dinners } & \multicolumn{8}{|c|}{ Frequency } \\
\hline & \multicolumn{2}{|c|}{ Never/rarely } & \multicolumn{2}{|c|}{ Sometimes } & \multicolumn{2}{|c|}{ Usually } & \multicolumn{2}{|c|}{ Always } \\
\hline & $\%$ & $n$ & $\%$ & $n$ & $\%$ & $n$ & $\%$ & $n$ \\
\hline Green salad & $17 \cdot 0$ & 325 & $54 \cdot 8$ & 1048 & $21 \cdot 5$ & 412 & $6 \cdot 7$ & 129 \\
\hline Vegetables & $3 \cdot 1$ & 59 & $26 \cdot 8$ & 511 & 39.5 & 754 & $30 \cdot 6$ & 585 \\
\hline Fruit juice & $27 \cdot 0$ & 514 & $43 \cdot 8$ & 834 & $18 \cdot 5$ & 352 & $10 \cdot 7$ & 204 \\
\hline Fruit & $21 \cdot 6$ & 410 & $45 \cdot 8$ & 869 & $21 \cdot 8$ & 414 & $10 \cdot 7$ & 203 \\
\hline Milk & $20 \cdot 5$ & 389 & $25 \cdot 7$ & 489 & $21 \cdot 0$ & 399 & $32 \cdot 8$ & 624 \\
\hline \multirow[t]{3}{*}{ Sugar-sweetened beverages } & $41 \cdot 7$ & 798 & $36 \cdot 4$ & 697 & $15 \cdot 1$ & 289 & $6 \cdot 9$ & 132 \\
\hline & \multicolumn{2}{|c|}{ Never } & \multicolumn{2}{|c|}{1 time } & \multicolumn{2}{|c|}{2 times } & \multicolumn{2}{|c|}{3 or more times } \\
\hline & $\%$ & $n$ & $\%$ & $n$ & $\%$ & $n$ & $\%$ & $n$ \\
\hline Fast food at family meal in past week & $38 \cdot 6$ & 741 & $\overline{40 \cdot 4}$ & 777 & $\overline{13.9}$ & $\overline{267}$ & $7 \cdot 1$ & 137 \\
\hline
\end{tabular}

*Only parents who reported eating family dinners were included in the analytic sample, see Methods section for details. 
Table 3 Adjusted ${ }^{*}$ percentages of families serving specific foods at family dinner on a regular basis (i.e. usually or always)t, and overall mean score for healthfulness of foods served, by parent/ family sociodemographics, psychosocial factors and meal-specific variables, for parents involved in food preparation who reported eating family dinner ( $n$ 1923), Project F-EAT (Families and Eating and Activity in Teens), St. Paul, MN, USA, 2009-2010

\begin{tabular}{|c|c|c|c|c|c|c|c|c|c|}
\hline & $n$ & $\begin{array}{c}\text { Green salad } \\
(\%)\end{array}$ & $\begin{array}{c}\text { Vegetables } \ddagger \\
(\%)\end{array}$ & $\begin{array}{l}\text { Fruit } \\
(\%)\end{array}$ & $\begin{array}{l}\text { Fruit juice } \\
(\%)\end{array}$ & $\begin{array}{l}\text { Milk } \\
(\%)\end{array}$ & $\begin{array}{l}\text { Sugared drinks } \\
(\%)\end{array}$ & $\begin{array}{l}\text { Fast food } \\
(\%)\end{array}$ & $\begin{array}{c}\text { Overall } \\
\text { healthfulness } \\
\text { score§: mean }\end{array}$ \\
\hline \multicolumn{10}{|l|}{ Sociodemographics } \\
\hline \multicolumn{10}{|l|}{ Educational attainment } \\
\hline$<$ High school & 537 & $28 \cdot 7$ & $64 \cdot 0$ & $32 \cdot 6$ & $26 \cdot 7$ & $52 \cdot 2$ & $25 \cdot 0$ & $24 \cdot 2$ & $4 \cdot 9$ \\
\hline High school or GED & 387 & $29 \cdot 1$ & $65 \cdot 5$ & $31 \cdot 9$ & $29 \cdot 1$ & $55 \cdot 9$ & $22 \cdot 6$ & $20 \cdot 8$ & $5 \cdot 3$ \\
\hline Some college & 538 & $24 \cdot 0$ & $75 \cdot 2$ & $29 \cdot 1$ & $27 \cdot 5$ & $53 \cdot 8$ & $23 \cdot 1$ & $24 \cdot 2$ & $5 \cdot 3$ \\
\hline Finished college & 327 & $27 \cdot 9$ & $76 \cdot 3$ & $35 \cdot 1$ & 34.5 & $59 \cdot 6$ & $19 \cdot 9$ & $16 \cdot 0$ & $6 \cdot 0$ \\
\hline Advanced degree & 116 & $39 \cdot 0$ & $78 \cdot 1$ & $35 \cdot 4$ & $32 \cdot 5$ & $44 \cdot 9$ & $7 \cdot 0$ & $13 \cdot 9$ & $6 \cdot 2$ \\
\hline$P$ value & & 0.043 & 0.002 & 0.512 & 0.338 & 0.073 & 0.013 & 0.029 & 0.002 \\
\hline \multicolumn{10}{|l|}{ Household income level } \\
\hline$<\$$ US 20000 & 664 & $28 \cdot 2$ & $70 \cdot 1$ & $34 \cdot 2$ & $31 \cdot 6$ & $55 \cdot 7$ & $23 \cdot 5$ & $25 \cdot 1$ & $5 \cdot 5$ \\
\hline \$US $20000-34999$ & 424 & $24 \cdot \overline{9}$ & $68 \cdot 9$ & $28 \cdot \overline{4}$ & 28.9 & $52 \cdot 4$ & $22 \cdot 3$ & $22 \cdot 1$ & $5 \cdot 2$ \\
\hline \$US 35000-49 999 & 281 & $27 \cdot 2$ & $68 \cdot 2$ & $31 \cdot 0$ & $23 \cdot 7$ & $54 \cdot 9$ & 23.9 & $17 \cdot 3$ & $5 \cdot 3$ \\
\hline \$US 50000-74999 & 226 & $26 \cdot 9$ & $68 \cdot 1$ & $32 \cdot 2$ & $27 \cdot 9$ & $51 \cdot 5$ & $21 \cdot 4$ & $22 \cdot 3$ & $5 \cdot 2$ \\
\hline$\geq \$$ US 75000 & 251 & $34 \cdot 7$ & $77 \cdot 7$ & $34 \cdot 1$ & $28 \cdot 0$ & $54 \cdot 8$ & $15 \cdot 5$ & $14 \cdot 4$ & $5 \cdot 8$ \\
\hline$P$ value & & 0.230 & 0.215 & 0.408 & 0.314 & 0.768 & 0.437 & 0.042 & 0.223 \\
\hline \multicolumn{10}{|l|}{ Ethnicity/race } \\
\hline White & 597 & $26 \cdot 1^{\mathrm{a}}$ & $75 \cdot 4^{\mathrm{a}}$ & $29 \cdot 5^{\mathrm{a}}$ & $18 \cdot 6^{\mathrm{b}}$ & $76 \cdot 6^{\mathrm{d}}$ & $12 \cdot 0^{\mathrm{a}}$ & $23 \cdot 6^{\mathrm{b}}$ & $5 \cdot 8^{b}$ \\
\hline Black & 544 & $30 \cdot 9^{a}$ & $74 \cdot 0^{\mathrm{a}}$ & $29 \cdot 8^{a}$ & $33 \cdot 5^{a}$ & $41 \cdot 1^{\mathrm{a}, \mathrm{b}}$ & $38 \cdot 0^{\mathrm{C}}$ & $27 \cdot 0^{\mathrm{b}}$ & $4 \cdot 8^{a}$ \\
\hline Hispanic/Latino & 320 & $30 \cdot 6^{\mathrm{a}}$ & $54 \cdot 1^{\mathrm{b}}$ & $36 \cdot 7^{\mathrm{a}}$ & $37 \cdot 7^{\mathrm{a}}$ & $53 \cdot 8^{c}$ & $22 \cdot 2^{\mathrm{b}}$ & $18 \cdot 1^{a, b}$ & $5 \cdot 3^{a, b}$ \\
\hline Asian American & 325 & $28 \cdot 3^{a}$ & $70 \cdot 2^{\mathrm{a}}$ & $36 \cdot 6^{\mathrm{a}}$ & $32 \cdot 1^{a}$ & $31 \cdot 2^{\mathrm{a}}$ & $10 \cdot 2^{\mathrm{a}}$ & $10 \cdot 9^{a}$ & $5 \cdot 6^{a, b}$ \\
\hline American Indian & 51 & $16 \cdot 5^{\mathrm{a}}$ & $83 \cdot 0^{\mathrm{a}}$ & $43 \cdot 1^{a}$ & $25 \cdot 5^{a, b}$ & $64 \cdot 2^{\mathrm{c}, \mathrm{d}}$ & $37 \cdot 7^{\mathrm{b}, \mathrm{c}}$ & $24 \cdot 8^{a, b}$ & $5 \cdot 2^{\mathrm{a}, \mathrm{b}}$ \\
\hline Other/mixed & 56 & $17 \cdot 9^{a}$ & $69 \cdot 9^{a, b}$ & $23 \cdot 9^{a}$ & $31 \cdot 7^{a, b}$ & $55 \cdot 6^{\mathrm{b}, \mathrm{c}, \mathrm{d}}$ & $15 \cdot 5^{a, b}$ & $27 \cdot 7^{\mathrm{a}, \mathrm{b}}$ & $5 \cdot 3^{a, b}$ \\
\hline$P$ value & & $0 \cdot 106$ & $<0.001$ & 0.088 & $<0.001$ & $<0.001$ & $<0.001$ & $<0.001$ & 0.002 \\
\hline \multicolumn{10}{|l|}{ Work status } \\
\hline Full-time & 873 & $28 \cdot 5$ & $69 \cdot 0$ & $28 \cdot 6$ & $26 \cdot 6$ & $51 \cdot 6$ & $23 \cdot 5$ & $24 \cdot 1$ & $5 \cdot 1$ \\
\hline Part-time & 327 & $29 \cdot 1$ & $73 \cdot 2$ & 34.9 & $29 \cdot 7$ & $57 \cdot 4$ & $19 \cdot 3$ & $20 \cdot 5$ & $5 \cdot 6$ \\
\hline Stay-at-home caregiver & 261 & $26 \cdot 1$ & $63 \cdot \overline{5}$ & $31 \cdot 4$ & $26 \cdot 3$ & $53 \cdot 8$ & $20 \cdot 9$ & $17 \cdot 4$ & $5 \cdot 4$ \\
\hline Unemployed & 428 & $27 \cdot 3$ & $74 \cdot 3$ & $37 \cdot 8$ & 34.5 & $57 \cdot 3$ & $23 \cdot 6$ & $19 \cdot 6$ & $5 \cdot 7$ \\
\hline$P$ value & & 0.881 & 0.016 & 0.023 & 0.052 & 0.192 & 0.382 & $0 \cdot 152$ & 0.058 \\
\hline \multicolumn{10}{|l|}{ Marital status } \\
\hline Single/divorced/other & 762 & $30 \cdot 2$ & $70 \cdot 2$ & $30 \cdot 6$ & $29 \cdot 7$ & $52 \cdot 2$ & $23 \cdot 3$ & $20 \cdot 2$ & $5 \cdot 3$ \\
\hline Married/partnership & 1141 & $26 \cdot 6$ & $70 \cdot 2$ & $33 \cdot 1$ & $28 \cdot 4$ & $55 \cdot 6$ & $21 \cdot 7$ & $22 \cdot 5$ & $5 \cdot 4$ \\
\hline$P$ value & & 0.156 & 0.979 & 0.350 & 0.615 & 0.196 & 0.454 & 0.316 & 0.309 \\
\hline \multicolumn{10}{|l|}{ Number of children at home } \\
\hline$<2$ & 411 & $30 \cdot 0$ & $67 \cdot 9$ & $29 \cdot 8$ & 28.9 & $48 \cdot 6$ & $20 \cdot 7$ & $24 \cdot 5$ & $5 \cdot 1$ \\
\hline 2 or 3 & 982 & $28 \cdot 3$ & $70 \cdot 9$ & $32 \cdot 7$ & $28 \cdot 5$ & $56 \cdot 2$ & $23 \cdot 6$ & $20 \cdot 2$ & $5 \cdot 5$ \\
\hline$>3$ & 477 & $25 \cdot 7$ & $70 \cdot 4$ & $33 \cdot 0$ & $29 \cdot 8$ & $54 \cdot 8$ & $21 \cdot 3$ & $21 \cdot 6$ & $5 \cdot 4$ \\
\hline$P$ value & & 0.485 & 0.582 & 0.602 & 0.886 & 0.044 & 0.396 & 0.264 & 0.332 \\
\hline \multicolumn{10}{|l|}{ Psychosocial factors } \\
\hline \multicolumn{10}{|l|}{ Work-life stress } \\
\hline High & 366 & $27 \cdot 9$ & $64 \cdot 8$ & $30 \cdot 2$ & $30 \cdot 9$ & $52 \cdot 5$ & $26 \cdot 4$ & $26 \cdot 5$ & $4 \cdot 9$ \\
\hline Moderate & 818 & $29 \cdot 5$ & $67 \cdot 7$ & $31 \cdot 0$ & $28 \cdot 1$ & $54 \cdot 2$ & $21 \cdot 4$ & $21 \cdot 0$ & $5 \cdot 3$ \\
\hline Low & 434 & $26 \cdot 2$ & $80 \cdot 4$ & $34 \cdot 4$ & $30 \cdot 2$ & $57 \cdot 1$ & $20 \cdot 6$ & $17 \cdot 5$ & $5 \cdot 8$ \\
\hline$P$ value & & 0.492 & $<0.001$ & 0.420 & 0.576 & 0.433 & $0 \cdot 122$ & 0.020 & 0.003 \\
\hline
\end{tabular}


Table 3 Continued

\begin{tabular}{|c|c|c|c|c|c|c|c|c|c|}
\hline & $n$ & $\begin{array}{c}\text { Green salad } \\
(\%)\end{array}$ & $\begin{array}{c}\text { Vegetables } \\
(\%)\end{array}$ & $\begin{array}{l}\text { Fruit } \\
(\%)\end{array}$ & $\begin{array}{l}\text { Fruit juice } \\
(\%)\end{array}$ & $\begin{array}{l}\text { Milk } \\
(\%)\end{array}$ & $\begin{array}{l}\text { Sugared drinks } \\
(\%)\end{array}$ & $\begin{array}{l}\text { Fast food } \\
(\%)\end{array}$ & $\begin{array}{c}\text { Overall } \\
\text { healthfulness } \\
\text { score§: mean }\end{array}$ \\
\hline \multicolumn{10}{|c|}{ Depressive symptoms } \\
\hline No & 1575 & $28 \cdot 5$ & $71 \cdot 1$ & $33 \cdot 1$ & $28 \cdot 4$ & $54 \cdot 5$ & $21 \cdot 0$ & $19 \cdot 5$ & $5 \cdot 5$ \\
\hline Yes & 291 & $25 \cdot 1$ & $65 \cdot 3$ & $29 \cdot 2$ & $29 \cdot 8$ & $53 \cdot 3$ & $30 \cdot 3$ & $32 \cdot 1$ & $4 \cdot 7$ \\
\hline$P$ value & & 0.272 & 0.057 & $0 \cdot 222$ & 0.657 & $0 \cdot 718$ & $<0.001$ & $<0.001$ & $<0.001$ \\
\hline \multicolumn{10}{|c|}{ Family functioning } \\
\hline Low & 362 & $23 \cdot 5$ & $63 \cdot 5$ & $26 \cdot 2$ & $26 \cdot 6$ & $49 \cdot 2$ & $28 \cdot 7$ & $22 \cdot 2$ & $4 \cdot 7$ \\
\hline Moderate & 1147 & $28 \cdot 0$ & $70 \cdot 5$ & $31 \cdot 1$ & $28 \cdot 7$ & $53 \cdot 9$ & $21 \cdot 1$ & $20 \cdot 9$ & $5 \cdot 4$ \\
\hline High & 346 & $33 \cdot 7$ & $79 \cdot 7$ & $41 \cdot 2$ & $32 \cdot 3$ & $60 \cdot 6$ & $21 \cdot 0$ & $22 \cdot 2$ & $6 \cdot 2$ \\
\hline$P$ value & & 0.022 & $<0.001$ & $<0.001$ & 0.294 & 0.012 & 0.013 & 0.833 & $<0.001$ \\
\hline \multicolumn{10}{|c|}{ Meal-specific variables } \\
\hline \multicolumn{10}{|c|}{ Importance of family meals } \\
\hline Low & 363 & $25 \cdot 1$ & $62 \cdot 8$ & $21 \cdot 0$ & $23 \cdot 9$ & $51 \cdot 7$ & $30 \cdot 5$ & $24 \cdot 6$ & $4 \cdot 4$ \\
\hline Moderate & 1176 & $28 \cdot 3$ & $69 \cdot 3$ & $33 \cdot 3$ & $29 \cdot 4$ & $53 \cdot 3$ & $20 \cdot 5$ & $21 \cdot 2$ & $5 \cdot 4$ \\
\hline High & 349 & $30 \cdot 5$ & $81 \cdot 3$ & $40 \cdot 9$ & $32 \cdot 2$ & $59 \cdot 4$ & $21 \cdot 5$ & $19 \cdot 1$ & $6 \cdot 2$ \\
\hline$P$ value & & 0.312 & $<0.001$ & $<0.001$ & 0.064 & 0.087 & $<0.001$ & 0.227 & $<0.001$ \\
\hline \multicolumn{10}{|c|}{ Food purchasing barriers } \\
\hline High & 516 & $19 \cdot 9$ & $58 \cdot 8$ & $24 \cdot 0$ & $24 \cdot 3$ & $50 \cdot 2$ & $25 \cdot 0$ & $21 \cdot 2$ & $4 \cdot 6$ \\
\hline Moderate & 872 & $27 \cdot 9$ & $72 \cdot 6$ & $29 \cdot 3$ & $29 \cdot 7$ & $55 \cdot 7$ & $21 \cdot 6$ & $21 \cdot 8$ & $5 \cdot 4$ \\
\hline Low & 501 & $36 \cdot 2$ & $77 \cdot 9$ & $44 \cdot 1$ & $31 \cdot 7$ & $55 \cdot 5$ & $21 \cdot 9$ & $20 \cdot 9$ & $6 \cdot 0$ \\
\hline$P$ value & & $<0.001$ & $<0.001$ & $<0.001$ & 0.035 & $0 \cdot 113$ & 0.315 & 0.935 & $<0.001$ \\
\hline \multicolumn{10}{|c|}{ Enjoyment of cooking } \\
\hline Low & 368 & $16 \cdot 7$ & $60 \cdot 4$ & $24 \cdot 4$ & $22 \cdot 3$ & $51 \cdot 8$ & $25 \cdot 3$ & $26 \cdot 7$ & $4 \cdot 3$ \\
\hline High & 1543 & $30 \cdot 7$ & $72 \cdot 5$ & $34 \cdot 0$ & $30 \cdot 4$ & $54 \cdot 8$ & $21 \cdot 7$ & $20 \cdot 2$ & $5 \cdot 6$ \\
\hline$P$ value & & $<0.001$ & $<0.001$ & $<0.001$ & 0.003 & $0 \cdot 312$ & $0 \cdot 152$ & $0 \cdot 011$ & $<0.001$ \\
\hline \multicolumn{10}{|c|}{ Meal planning } \\
\hline Low & 497 & $20 \cdot 5$ & $66 \cdot 2$ & $24 \cdot 8$ & $21 \cdot 6$ & $46 \cdot 1$ & $26 \cdot 0$ & $27 \cdot 5$ & $4 \cdot 4$ \\
\hline High & 1414 & $30 \cdot 7$ & $71 \cdot 4$ & $34 \cdot 6$ & $31 \cdot 3$ & $56 \cdot 8$ & $21 \cdot 3$ & $19 \cdot 4$ & $5 \cdot 7$ \\
\hline$P$ value & & $<0.001$ & 0.039 & $<0.001$ & $<0.001$ & $<0.001$ & 0.039 & $<0.001$ & $<0.001$ \\
\hline \multicolumn{10}{|c|}{ Hours in food preparation } \\
\hline $0-7$ & 493 & $26 \cdot 6$ & $67 \cdot 6$ & $27 \cdot 2$ & $24 \cdot 4$ & $49 \cdot 8$ & $21 \cdot 6$ & $25 \cdot 9$ & 4.9 \\
\hline $8-18$ & 915 & $27 \cdot 4$ & $71 \cdot 0$ & $31 \cdot 8$ & $29 \cdot 5$ & $54 \cdot 8$ & $22 \cdot 5$ & $19 \cdot 0$ & $5 \cdot 4$ \\
\hline$>18$ & 421 & $32 \cdot 2$ & $72 \cdot 7$ & $38 \cdot 7$ & $32 \cdot 7$ & 58.0 & $22 \cdot 0$ & $21 \cdot 0$ & $6 \cdot 0$ \\
\hline$P$ value & & $0 \cdot 201$ & 0.250 & 0.005 & 0.039 & 0.052 & 0.924 & $0 \cdot 017$ & $<0.001$ \\
\hline
\end{tabular}

b,c,d Values within a column with unlike superscript letters were significantly different in pairwise tests $(P<0.05)$

*All models are adjusted for age, race, education, income, gender, work status, marital status and number of children. The $P$ value listed is from a likelihood ratio test examining an overall difference in proportions between the levels of a covariate.

tOr at least two times per week for fast food.

\$Not including potatoes.
§Summary score for all foods shown. Salad, vegetables, fruit juice, fruit and milk are coded as healthy and sugared drinks (i.e. sugar-sweetened beverages) and fast food as unhealthy (possible range: -6 to 15 ). 


\section{Psychosocial factors}

Higher levels of work-life stress, the presence of depressive symptoms and low levels of family functioning were all strongly associated with lower healthfulness of family meals in adjusted analyses ( $P$ values ranged from $P=0.003$ to $P=0 \cdot 001$; Table 3 ). Parents who reported higher levels of work-life stress were less likely to serve vegetables on a regular basis $(P<0 \cdot 001)$ and more likely to serve fast food $(P=0 \cdot 020)$. Parents reporting depressive symptoms were more likely to serve sugar-sweetened beverages and fast food (both $P<0 \cdot 001$ ). Finally, family functioning was positively associated with serving green salad $(P=0.022)$, vegetables, fruit (both $P<0.001)$ and milk $(P=0 \cdot 012)$ on a regular basis and inversely associated with sugared drinks $(P=0 \cdot 013)$.

\section{Meal-specific variables}

Perceiving family meals as important, enjoyment of cooking, meal planning and hours in food preparation were all positively associated with overall healthfulness of family meals (all $P<0 \cdot 001$ ), while reporting more food purchasing barriers was inversely associated with healthfulness scores $(P<0 \cdot 001)$. Additionally, many associations were also seen between these variables and specific types of foods served at family meals, as shown in Table 3.

\section{Discussion}

Findings from the current study suggest that, in many homes, healthy foods such as vegetables and milk are commonly served at family meals. But findings also indicate that in one-fifth of households, sugar-sweetened beverages and fast food are served on a regular basis. Some differences in the overall healthfulness of foods served at family meals were found across sociodemographic characteristics, in particular across levels of parent education. However, psychosocial factors and meal-specific variables were more consistently associated with the types of foods served at meals. Psychosocial factors including high levels of work-life stress, reported depressive symptoms and low levels of family functioning were strongly associated with lower healthfulness of family meals. Finally, all of the meal-specific variables assessed were strongly correlated with healthfulness of foods served at family meals. Findings provide insight into the types of factors to be addressed within interventions aimed at improving the food environment of family meals.

Associations between various sociodemographic characteristics and types of foods served at family meals were examined in order to identify population groups that might benefit most from interventions. Some differences in the overall healthfulness of foods served at family dinners were found across sociodemographic characteristics; in particular, parent educational attainment was inversely associated with the healthfulness of foods served at family meals. Given that the association was strong even after mutual adjustment for other sociodemographic characteristics, this finding suggests both the importance of parent education for family health and a need for ensuring that interventions around family meals are suitable for, and reach out to, parents with lower levels of educational attainment. Some differences across ethnicity/race were also observed; for example, sugared drinks were served most often in the homes of African Americans and American Indians, while sugared drinks and fast food were served least often in the homes of Asian Americans. Moreover, previous research has shown that weekly purchases of fast food for family dinner is significantly and positively associated with mean percentage body fat, metabolic risk scores and insulin levels among adolescents ${ }^{(48)}$. These findings suggest a need for the tailoring of intervention messages for different ethnic/racial subgroups. Interestingly, associations between work status and the types of foods served at family meals were much weaker and less consistent than associations with work-life stress. In a previous examination we similarly found that the subjective experience of work-life stress was more strongly correlated with a number of measures of parent dietary intake and the home food environment than the actual work status of parents ${ }^{(49)}$.

The strong associations found between psychosocial factors including work-life stress, depressive symptoms and family functioning, and overall healthfulness of food served at family meals, highlight the importance of addressing factors beyond those directly related to food (e.g. cooking skills) that may be serving as barriers to the preparation of healthy foods at family meals. Findings from the current study are in line with previous research findings indicating that stress from competing demands on parents' time may influence family meals ${ }^{(50-53)}$. Past research has shown a relationship between parent depressive symptoms and decreased positive parenting behaviours (e.g. related to communication, emotional closeness and setting limits) and increased negative parenting behaviours (e.g. conflict, disengagement, inability to attend to daily routines) ${ }^{(54,55)}$; thus it may be the case that parents struggle with maintaining daily routines such as serving healthy foods at family meals because they are challenged with managing depressive symptoms. Additionally, all of the meal-specific variables examined in the current study were strongly associated with the healthfulness of foods served at family meals. Meal planning was associated with all of the specific types of foods served at family meals; more planning was always correlated with healthier options (e.g. higher levels of vegetables and lower levels of fast food). Similarly, McIntosh and colleagues found that meal-specific variables, such as mothers' belief in the importance of family meals and meal planning practices, are correlated with 
the frequency of family dinners ${ }^{(56)}$. These findings indicate a need for the development of interventions that are broad in scope, and either directly address or take into account psychosocial stressors facing families. Findings also suggest a need for interventions that provide specific skills related to meal planning and preparation.

Study strengths include the high response rate, the large and diverse nature of the study population, the assessment of different types of foods served at family dinner, and the inclusion of various measures of parent characteristics (e.g. work-life stress, depressive symptoms). However, the study also had limitations that should be taken into account in interpreting the findings. Many of the variables were assessed with brief tools, in order to reduce participant burden and enhance parent response. For example, a short scale was used to assess depressive symptoms, some variables were measured with only one item (e.g. enjoyment of cooking), and the measure of types of foods served at family meals only assessed seven fairly broad categories of foods. Thus, conclusions from the current study should be made cautiously; for example, some of the fast food options served at family meals may have been healthy choices. Further replication studies that utilize more comprehensive measures are needed. Furthermore, all items were assessed via self-report, and assuming some degree of social desirability, it may be that the healthier food options are served less frequently and the poorer food options served more frequently than described here. Finally, the study included cross-sectional data and thus conclusions about the temporality of associations cannot be drawn.

The current study expands upon the existing research on family meals, which has primarily focused on the frequency of family meals and associations with child and adolescent outcomes. Little research has focused on the types of foods served at family meals and most existing studies have included very limited measures of the types of foods being served ${ }^{(11,14,38,57)}$. In an informative study on family meals among adolescents in Australia ${ }^{(58)}$, adolescents were asked to describe what they ate the previous day at dinner; this strategy offers a simple solution to learning more about the types of foods consumed at meals, although quantifying results can be difficult from such an open-ended question. Further research is needed to better understand the types of foods being served at family meals using more comprehensive measures and objective assessments such as unobtrusive observations of family meals. Research should also explore associations between the types of foods served at family meals and overall dietary intake and health outcomes (e.g. weight status), since different foods served at family meals may be consumed by different family members, and given that family members eat in various settings throughout the day (e.g. school, work). It is also important to learn more about those families who never eat family dinners together. In the current study, parents who reported they never ate family dinners did not differ from other parents in terms of age, employment status, marital status or number of children, but did have lower levels of educational attainment and income, and were more likely to be white and male. More information is needed to guide the development of interventions for these families. Finally, research is also needed to explore how to improve the dietary quality of family meals, taking into account the realities faced by modern-day families, particularly those with fewer resources (e.g. lower educational background) and greater stresses (e.g. due to challenges faced in balancing work-life stresses).

Findings from the current study suggest a need for interventions aimed at improving the healthfulness of foods served at family meals. Dietitians and other healthcare providers working with parents should take the time to explore the types of foods being served at family meals, as well as barriers to eating together as a family and serving healthful meals. Given the high percentage of fast foods being eaten at family meals, it is important to discuss healthier options for food choices at fast-food restaurants (e.g. pizza with vegetables instead of sausage, smaller portion sizes) and healthier alternatives to fast food that can be made quickly at home (e.g. foods that can be made quickly such as bagged and prewashed salads, sandwiches made at home with wholegrain bread). Community interventions and public policies are also important in order to ensure that affordable, healthful food options are readily available and help families work healthful family meals into their routines ${ }^{(59,60)}$. Interventions should be appropriate for parents with low levels of education, address different eating patterns across ethnic/racial groups, and take into account the busy lifestyles and other stressors facing parents. Finally, findings suggest the importance of enhancing parental attitudes toward family meals and providing specific skills to make it easier to plan and prepare healthful family meals.

\section{Acknowledgements}

Sources of funding: The project described was supported by Award Number R01HL093247 from the National Heart, Lung, and Blood Institute. The content is solely the responsibility of the authors and does not necessarily represent the official views of the National Heart, Lung, and Blood Institute or the National Institutes of Health. Conflicts of interest: The authors certify that they have no conflicts of interest. Authors' contributions: D.N.S. is the Principal Investigator on the study and wrote the manuscript. R.M. conducted data analysis. K.L., J.A.F., M.E.E. and J.B. were involved in study implementation and contributed to the interpretation of results and manuscript revisions. 


\section{References}

1. Woodruff SJ \& Hanning RM (2008) A review of family meal influence on adolescents' dietary intake. Can J Diet Pract Res 69, 14-22.

2. Feldman S, Eisenberg M, Neumark-Sztainer D et al. (2007) Associations between watching TV during family meals and dietary intake among adolescents. J Nutr Educ Behav 39, 257-263.

3. Burgess-Champoux TL, Larson NI, Neumark-Sztainer D et al. (2009) Are family meal patterns associated with overall diet quality during the transition from early to middle adolescence? J Nutr Educ Behav 41, 79-86.

4. Larson NI, Neumark-Sztainer D, Hannan PJ et al. (2007) Family meals during adolescence are associated with higher diet quality and healthful meal patterns during young adulthood. J Am Diet Assoc 107, 1502-1510.

5. Videon TM \& Manning CK (2003) Influences on adolescent eating patterns: the importance of family meals. $J$ Adolesc Health 32, 365-373.

6. Gillman MW, Rifas-Shiman SL, Frazier AL et al. (2000) Family dinner and diet quality among older children and adolescents. Arch Fam Med 9, 235-240.

7. Neumark-Sztainer D, Hannan PJ, Story M et al. (2003) Family meal patterns: associations with sociodemographic characteristics and improved dietary intake among adolescents. J Am Diet Assoc 103, 317-322.

8. Neumark-Sztainer D (2006) Eating among teens: do family mealtimes make a difference for adolescents' nutrition? New Dir Child Adolesc Dev issue 111, 91-105.

9. Veugelers PJ, Fitzgerald AL \& Johnston E (2005) Dietary intake and risk factors for poor diet quality among children in Nova Scotia. Can J Public Health 96, 212-216.

10. Hannon PA, Bowen DJ, Moinpour CM et al. (2003) Correlations in perceived food use between the family food preparer and their spouses and children. Appetite $\mathbf{4 0}$, 77-83.

11. Vejrup K, Lien N, Klepp KI et al. (2008) Consumption of vegetables at dinner in a cohort of Norwegian adolescents. Appetite 51, 90-96.

12. Woodruff SJ \& Hanning RM (2009) Effect of meal environment on diet quality rating. Can J Diet Pract Res 70, 118-124.

13. Woodruff SJ, Hanning RM, McGoldrick K et al. (2010) Healthy eating index-C is positively associated with family dinner frequency among students in grades 6-8 from Southern Ontario, Canada. Eur J Clin Nutr 64, 454-460.

14. MacFarlane A, Crawford D, Ball K et al. (2007) Adolescent home food environments and socioeconomic position. Asia Pac J Clin Nutr 16, 748-756.

15. Rollins BY, Belue RZ \& Francis LA (2010) The beneficial effect of family meals on obesity differs by race, sex, and household education: the national survey of children's health, 2003-2004. J Am Diet Assoc 110, 1335-1339.

16. Gable S, Chang Y \& Krull JL (2007) Television watching and frequency of family meals are predictive of overweight onset and persistence in a national sample of school-aged children. J Am Diet Assoc 107, 53-61.

17. Sen B (2006) Frequency of family dinner and adolescent body weight status: evidence from the National Longitudinal Survey of Youth, 1997. Obesity (Silver Spring) 14, 2266-2276.

18. Eaton DK, Kann L, Kinchen S et al. (2006) Youth risk behavior surveillance - United States, 2005. MMWR CDC Surveill Summ 55, 1-108.

19. Koplan JP, Liverman CT \& Kraak VI (2005) Preventing childhood obesity: health in the balance: executive summary. I Am Diet Assoc 105, 131-138.

20. Spear BA (2002) Adolescent growth and development. J Am Diet Assoc 102, 3 Suppl., S23-S29.
21. Story M, Holt K \& Sofka D (editors) (2000) Bright Futures in Practice: Nutrition. Arlington, VA: National Center for Education in Maternal and Child Health.

22. Cook A \& Friday J (2005) Pyramid Servings Intakes in the United States 1999-2002, 1 Day. Beltsville, MD: US Department of Agriculture; available at http://www.ba.ars. usda.gov/cnrg

23. Moshfegh A, Goldman J \& Cleveland L (2005) What We Eat in America, NHANES 2001-2002: Usual Nutrient Intakes from Food Compared to Dietary Reference Intakes. Beltsville, MD: US Department of Agriculture, Agricultural Research Service; available at http://www.ars.usda.gov/ba/ bhnrc/fsrg

24. Haines J, Gillman MW, Rifas-Shiman S et al. (2010) Family dinner and disordered eating behaviors in a large cohort of adolescents. Eat Disord 18, 10-24.

25. Worobey J (2002) Early family mealtime experiences and eating attitudes in normal weight, underweight and overweight females. Eat Weight Disord 7, 39-44.

26. Miller DAF, McCluskey-Fawcett K \& Irving LM (1993) Correlates of bulimia nervosa: early family mealtime experiences. Adolescence 28, 621-635.

27. Fulkerson JA, Neumark-Sztainer D, Hannan PJ et al. (2008) Family meal frequency and weight status among adolescents: cross-sectional and five-year longitudinal associations. Obesity (Silver Spring) 16, 2529-2534.

28. Ackard D \& Neumark-Sztainer D (2001) Family mealtime while growing up: associations with symptoms of bulimia nervosa. Eat Disord 9, 239-249.

29. Neumark-Sztainer D, Eisenberg ME, Fulkerson JA et al. (2008) Family meals and disordered eating in adolescents: longitudinal findings from Project EAT. Arch Pediatr Adolesc Med 162, 17-22.

30. Neumark-Sztainer D, Wall M, Story M et al. (2004) Are family meal patterns associated with disordered eating behaviors among adolescents? J Adolesc Health 35, 350-359.

31. Eisenberg ME, Olson RE, Neumark-Sztainer D et al. (2004) Correlations between family meals and psychosocial wellbeing among adolescents. Arch Pediatr Adolesc Med 158, 792-796.

32. Bowden BS, Zeisz JM (1997) Supper's on! Adolescent adjustment and frequency of family mealtimes. Paper presented at 105th Annual Meeting of the American Psychological Association, Chicago, IL, 15-19 August 1997.

33. Hammons AJ \& Fiese BH (2011) Is frequency of shared family meals related to the nutritional health of children and adolescents? Pediatrics 127, e1565-e1574.

34. Cho S, Dietrich M, Brown CJ et al. (2003) The effect of breakfast type on total daily energy intake and body mass index: results from the Third National Health and Nutrition Examination Survey (NHANES III). J Am Coll Nutr 22, 296-302.

35. Bandura A (1986) Social Foundations of Thought and Action: A Social Cognitive Theory. Englewood Cliffs, NJ: Prentice-Hall, Inc.

36. Sallis JF, Owen N, Fisher EB (2008) Ecological models of health behavior. In Health Behavior and Health Education: Theory, Research, and Practice, 4th ed., pp. 465-485 [K Glanz, BK Rimer and K Viswanath editors]. San Francisco, CA: Jossey-Bass.

37. Fulkerson JA, Lytle L, Story M et al. (2012) Development and validation of a screening instrument to assess the types and quality of foods served at home meals. Int J Behav Nutr Phys Act 9, 10.

38. Boutelle K, Fulkerson JA, Neumark-Sztainer D et al. (2007) Fast food for family meals: relationships with parent and adolescent food intake, home food availability and weight status. Public Health Nutr 10, 16-23.

39. Marshall NL \& Barnett RC (1991) Race, class and multiple role strains and gains among women employed in the service sector. Women Health 17, 1-19. 
40. Marshall NL \& Barnett RC (1993) Work-family strains and gains among 2-earner couples. J Community Psychol 21, 64-78.

41. Bohannon RW, Maljanian R \& Goethe J (2003) Screening for depression in clinical practice: reliability and validity of a five-item subset of the CES-Depression. Percept Mot Skills 97, 855-861.

42. Epstein NB, Baldwin LM \& Bishop D (1983) The McMaster family assessment device. J Marital Fam Ther 9, 171-180.

43. Hogen PD (1988) The relationship between individual psychological characteristics and factors associated with family use of food as predictors of disturbed eating attitudes and behaviors in adolescents. Doctoral Dissertation, University of Hartford.

44. Campbell KJ, Crawford DA, Salmon J et al. (2007) Associations between the home food environment and obesity-promoting eating behaviors in adolescence. Obesity (Silver Spring) 15, 719-730.

45. Hardy LL, Baur LA, Garnett SP et al. (2006) Family and home correlates of television viewing in 12-13 year old adolescents: The Nepean Study. Int J Behav Nutr Phys Act 3, 24.

46. Demo DH \& Acock AC (1993) Family diversity and the division of domestic labor: how much have things really changed? Fam Relat 42, 323-331.

47. Localio AR, Margolis DJ \& Berlin JA (2007) Relative risks and confidence intervals were easily computed indirectly from multivariable logistic regression. J Clin Epidemiol 60 , 874-882.

48. Fulkerson JA, Farbakhsh K, Lytle L et al. (2011) Away-fromhome family dinner sources and associations with weight status, body composition, and related biomarkers of chronic disease among adolescents and their parents. $J$ Am Diet Assoc 111, 1892-1897.

49. Bauer K, Hearst MO, Escoto KH et al. (2012) Parental employment and work-family stress: Associations with family food environment. Soc Sci Med 75, 496-504.
50. Fulkerson JA, Story M, Neumark-Sztainer D et al. (2008) Family meals: perceptions of benefits and challenges among parents of 8- to 10-year-old children. J Am Diet Assoc 108, 706-709.

51. Devine CM, Jastran M, Jabs J et al. (2006) 'A lot of sacrifices': work-family spillover and the food choice coping strategies of low-wage employed parents. Soc Sci Med 63, 2591-2603.

52. Devine CM, Connors MM, Sobal J et al. (2003) Sandwiching it in: spillover of work onto food choices and family roles in low- and moderate-income urban households. Soc Sci Med 56, 617-630.

53. Devine CM, Farrell TJ, Blake CE et al. (2009) Work conditions and the food choice coping strategies of employed parents. J Nutr Educ Behav 41, 365-370.

54. Lovejoy MC, Graczyk PA, O'Hare E et al. (2000) Maternal depression and parenting behavior: a meta-analytic review. Clin Psychol Rev 20, 561-592.

55. Wilson S \& Durbin CE (2010) Effects of paternal depression on fathers' parenting behaviors: a meta-analytic review. Clin Psychol Rev 30, 167-180.

56. McIntosh WA, Kubena KS, Tolle G et al. (2010) Mothers and meals. The effects of mothers' meal planning and shopping motivations on children's participation in family meals. Appetite 55, 623-628.

57. Jacobs MP \& Fiese BH (2007) Family mealtime interactions and overweight children with asthma: potential for compounded risks? J Pediatr Psychol 32, 64-68.

58. Gallegos D, Dziurawiec S, Fozdar F et al. (2011) Adolescent experiences of 'family meals' in Australia. J Sociol 47, 243.

59. Story M \& Neumark-Sztainer D (2005) A perspective on family meals: do they matter? Nutr Today 40, 261-266.

60. Fiese BH \& Schwartz M (2008) Reclaiming the family table: mealtimes and child health and wellbeing. Soc Policy Rep XXII, issue IV, 3-19. 